\title{
Theoretical studies on the mechanism of $\mathrm{C}-\mathrm{P}$ bond cleavage of a model $\alpha$-aminophosphonate in acidic condition
}

Marek Doskocz, ${ }^{a, b}$ Szczepan Roszak, ${ }^{a, c}$ D. Majumdar, ${ }^{a}$ Jacek Doskocz, ${ }^{b}$ Roman Gancarz, ${ }^{b}$ and Jerzy Leszczynski ${ }^{a^{*}}$

${ }^{a}$ Computational Center for Molecular Structure and Interactions, Jackson State University, Jackson, MS 39217

${ }^{b}$ Department of Medicinal Chemistry and Microbiology, Faculty of Chemistry, Wroclaw

University of Technology, Wyb. Wyspianskiego 27; 50-370 Wroclaw, Poland

${ }^{c}$ Institute of Physical and Theoretical Chemistry, Wroclaw University of Technology, Wybrzeże Wyspiańskiego 27, 50-370 Wroclaw,

Poland 


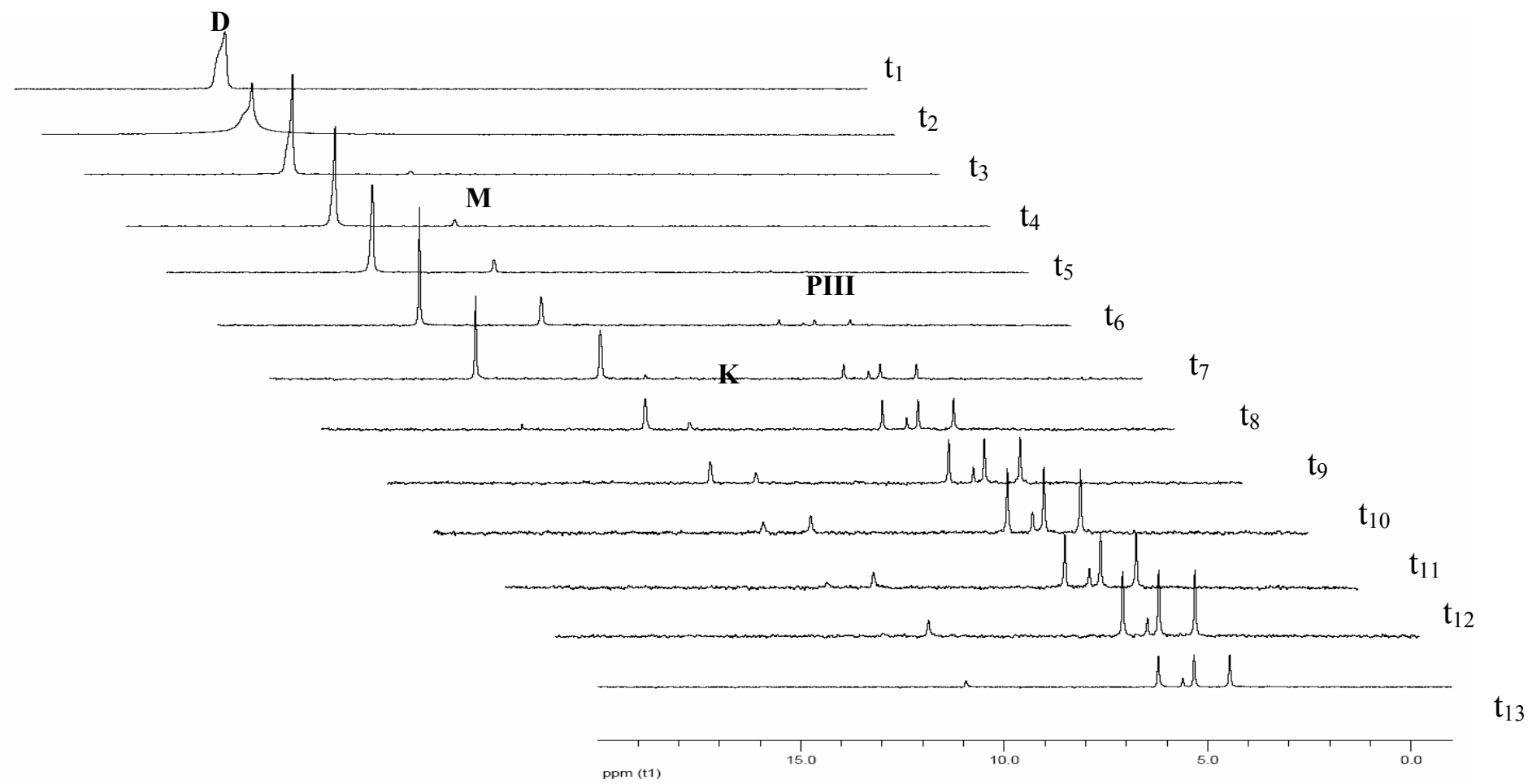

Fig. 1s. ${ }^{31} \mathrm{P}\left\{{ }^{1} \mathrm{H}\right\}$ NMR time dependent spectra for $13 \% \mathrm{HCl}$ solution in $90.0^{\circ} \mathrm{C}$. The elements of solution: D - diester, $\mathrm{M}-\mathrm{monoester}$, $\mathrm{K}$ - ( $\alpha$-anilinobenzyl)phosphonates, and PIII - phosphonic acid. The spectral studies were carried out in the experimental lab of the present authors. 


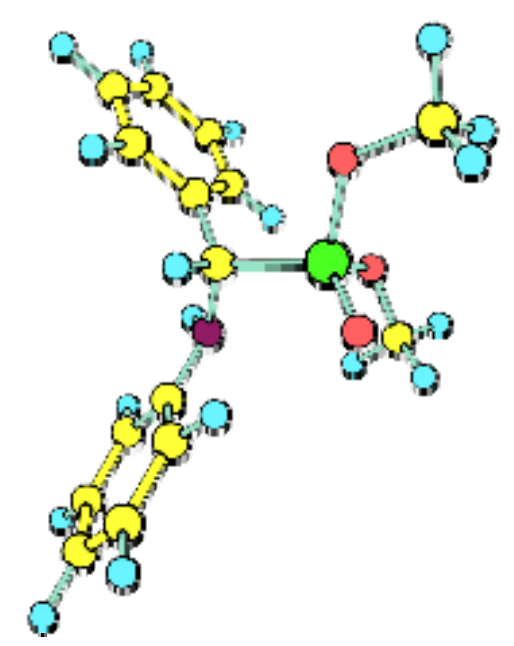

MI

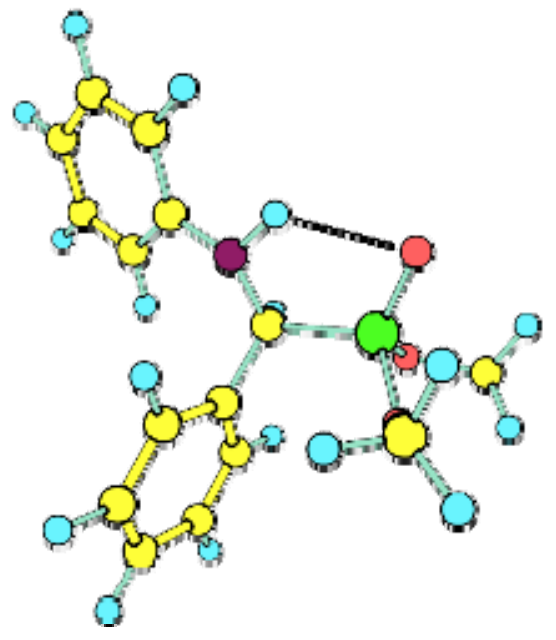

$$
\begin{gathered}
\mathrm{M} 4 \\
l_{\mathrm{NH} \cdots \mathrm{O}}=2.202 \AA
\end{gathered}
$$

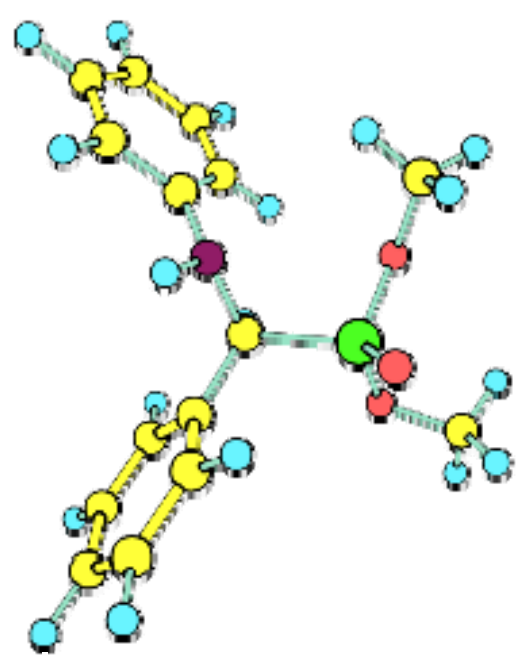

M2

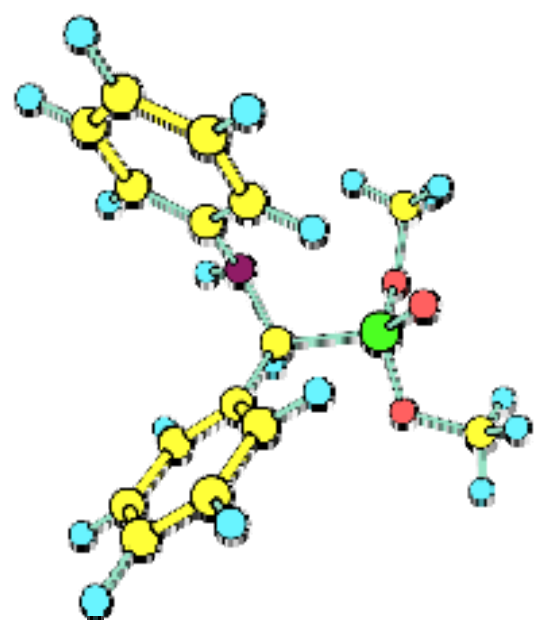

M5

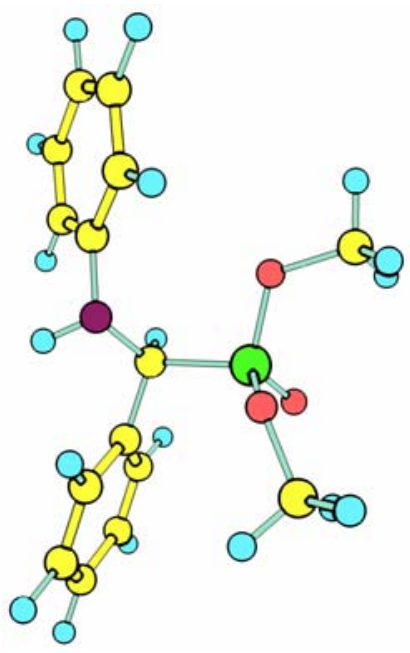

MB

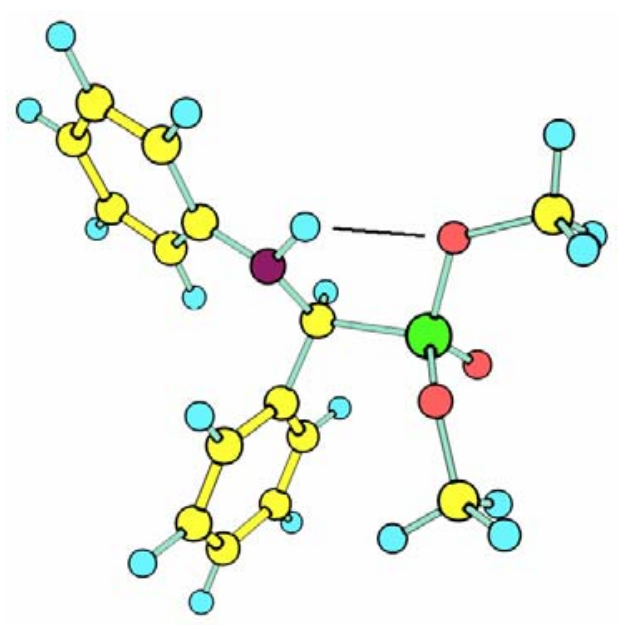

$$
\begin{array}{r}
\mathrm{M} 6 \\
l_{\mathrm{NH} \cdots \mathrm{O}}=2.233 \AA
\end{array}
$$

Fig. 2s. The structures of low energy conformers of dimethyl ( $\alpha$-anilinobenzyl) phosphorate (DMABP) molecule 


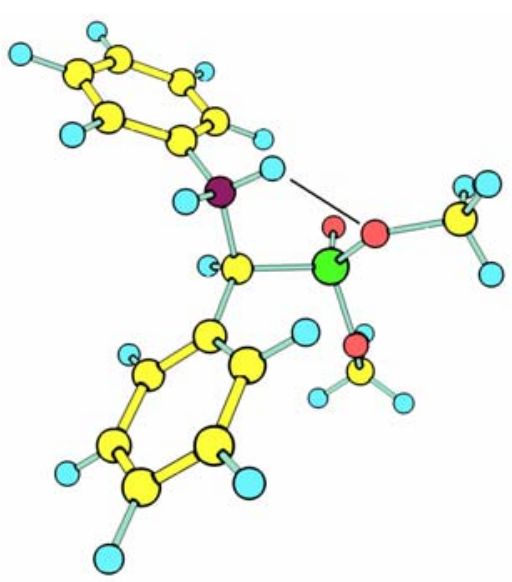

$\mathrm{NH}^{+} 1$

$l_{\mathrm{NH} \cdots \mathrm{O}}=2.110 \AA$

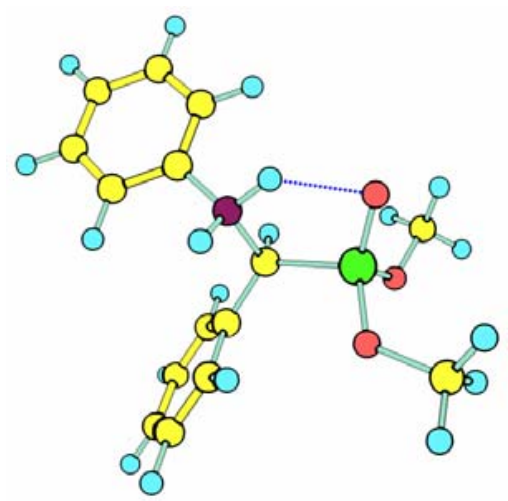

$\mathrm{NH}^{+} 4$

$l_{\mathrm{NH} \cdots \mathrm{O}}=1.910 \AA$

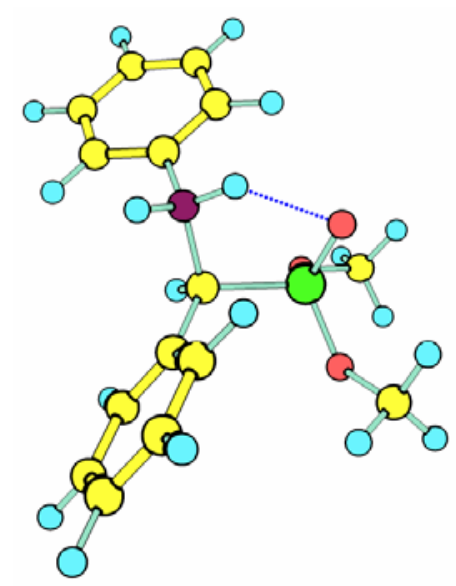

$\mathbf{N H}^{+} \mathbf{2}$

$l_{\mathrm{NH} \cdots \mathrm{O}}=1.954 \AA$

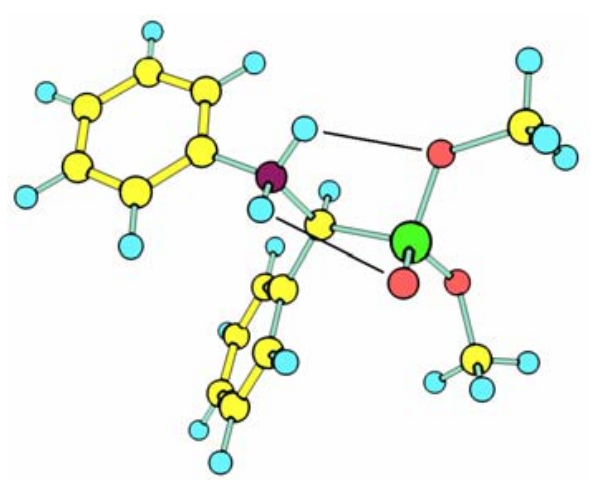

$\mathrm{NH}^{+} 5$

$l_{\mathrm{NH} \cdots \mathrm{O}}=2.425,2.560 \AA$

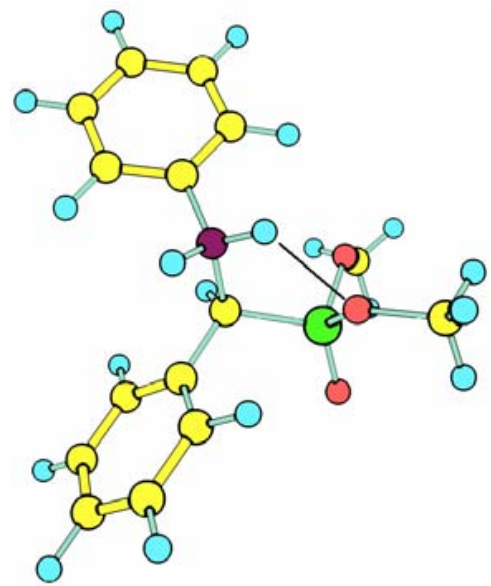

$\mathrm{NH}^{+} 3$

$l_{\mathrm{NH} \cdots \mathrm{O}}=2.061 \AA$

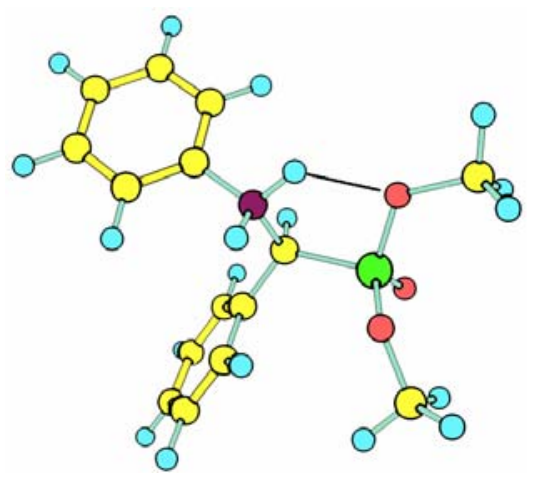

$\mathrm{NH}^{+} 6$

$l_{\mathrm{NH} \cdots \mathrm{O}}=2.015 \AA$

Fig. 3s. The structures of low energy conformers of protonated DMABP on amino fragment 


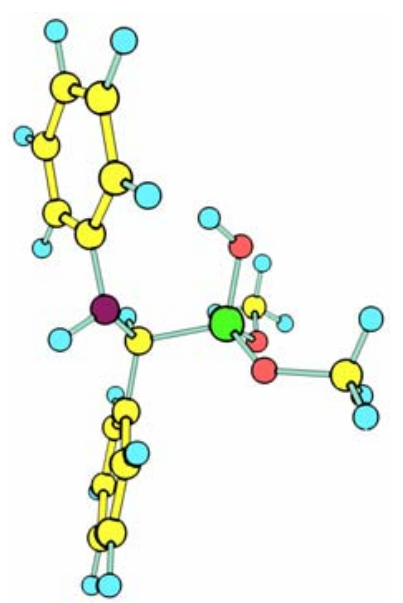

$\mathrm{OH}^{+} 1$

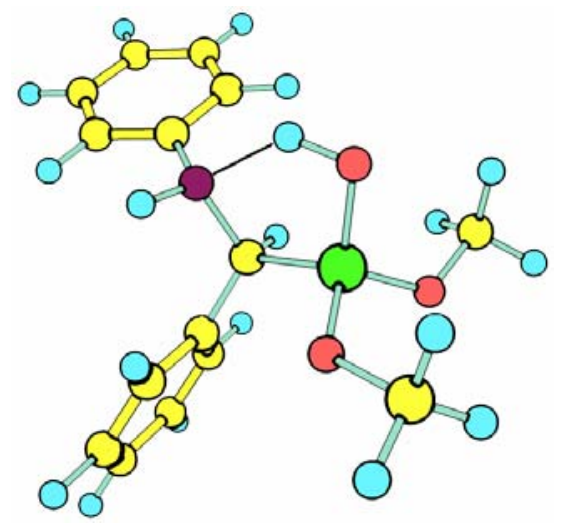

$\mathrm{OH}^{+} 4$

$l_{\mathrm{POH} \cdots \mathrm{N}}=1.846 \AA$

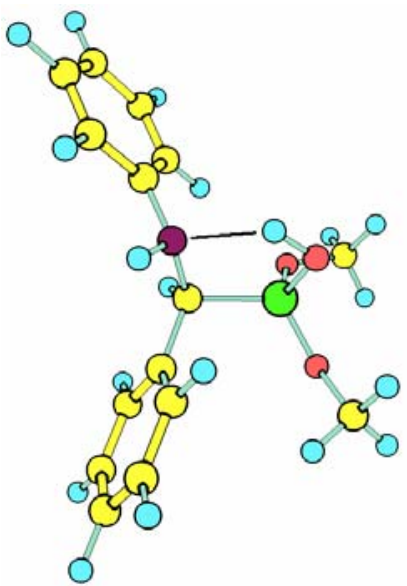

$\mathrm{OH}^{+} \mathbf{2}$

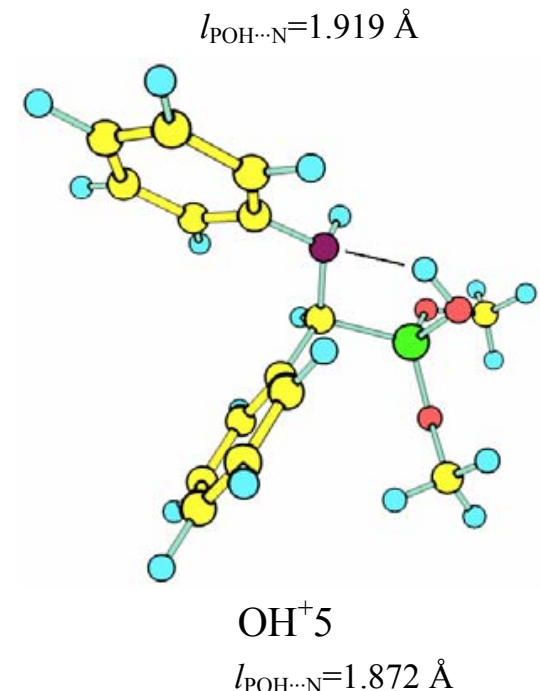

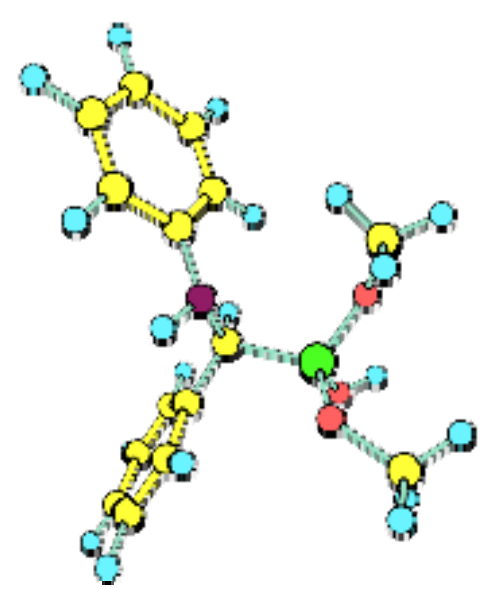

$\mathrm{OH}^{+} 3$

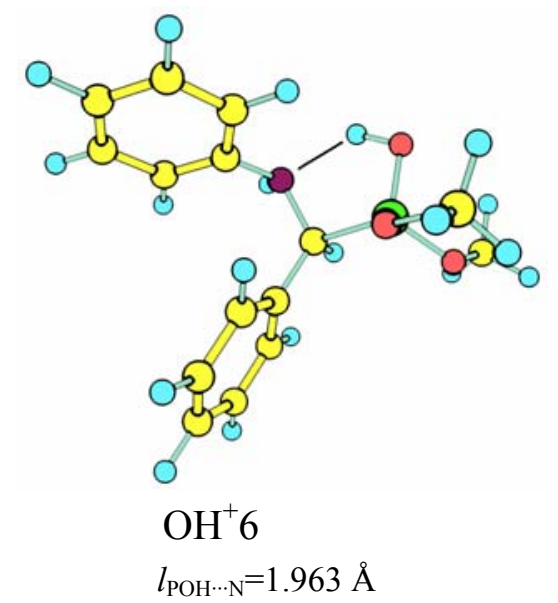

Fig. 4s. The structures of low energy conformers of protonated DMABP on phosphoryl oxygen 


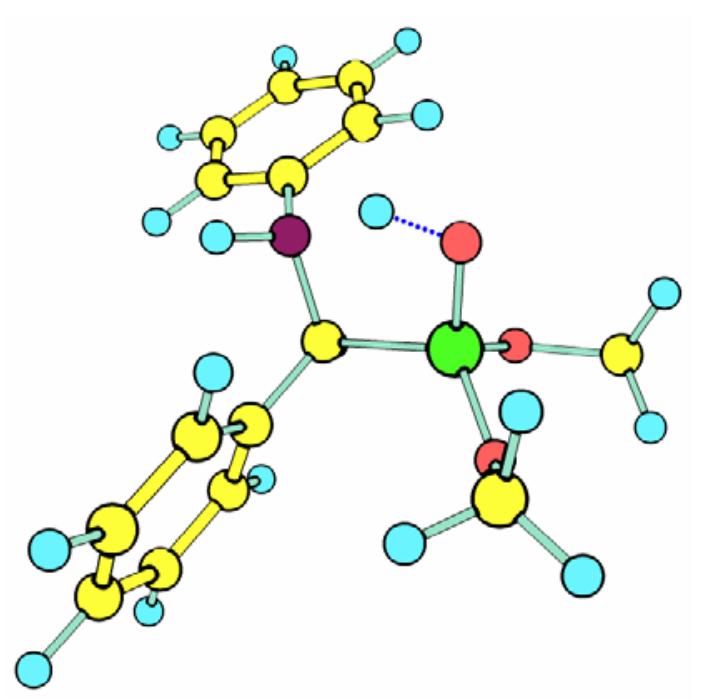

$\mathrm{TS}\left(\mathrm{NH}^{+} \mathrm{O}\right)$

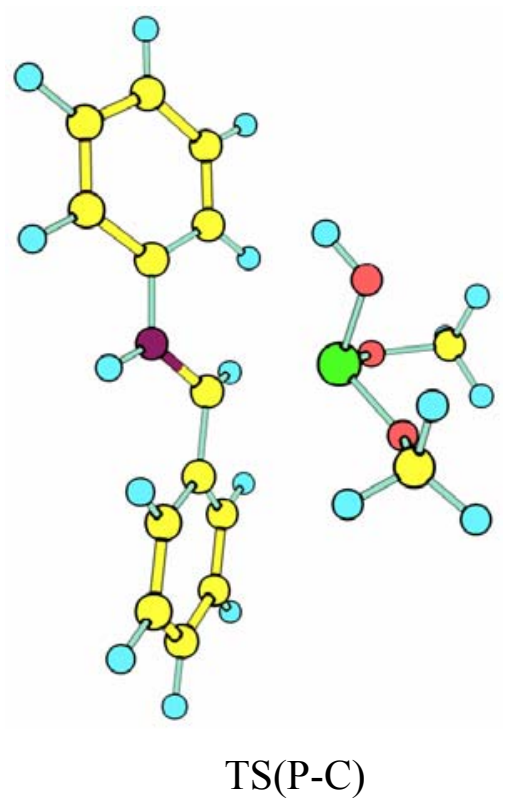

Fig $5 \mathrm{~s}$. The structures of transition states characterising the first reaction mechanism 


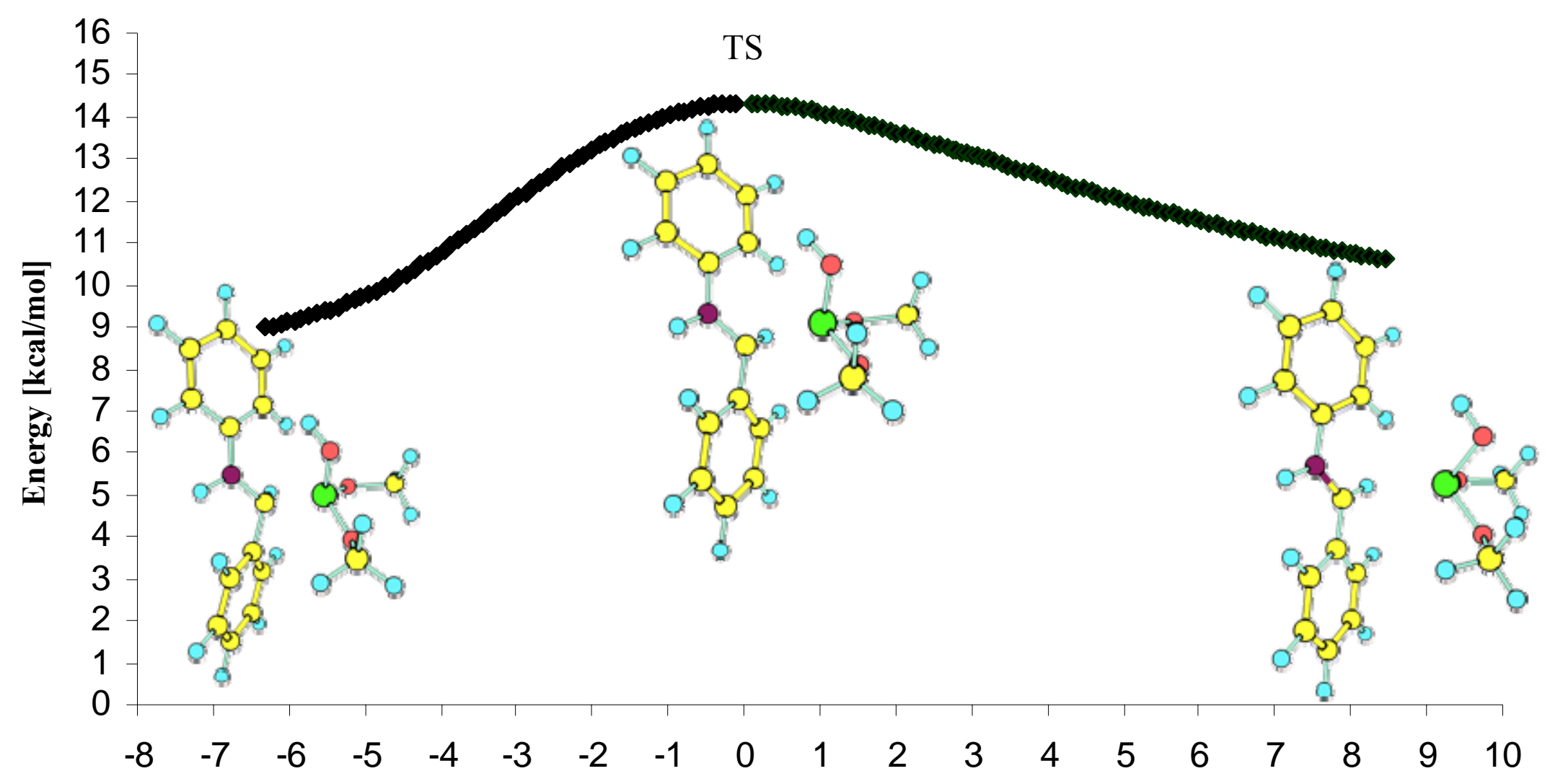

Fig. 6s The IRC pathway for the P-C cleavage according to the first mechanism 


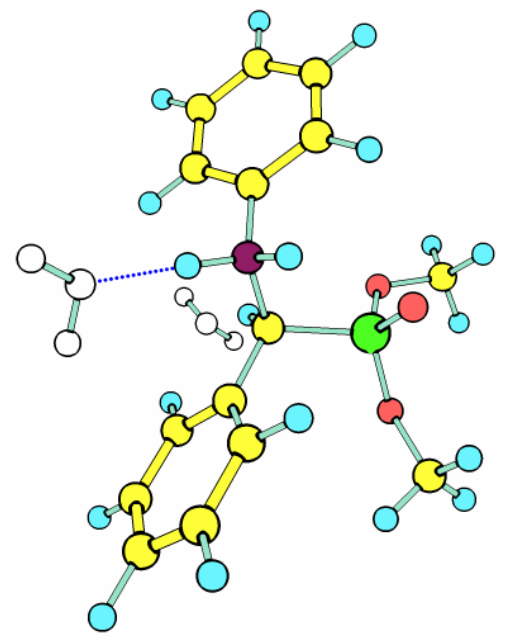

$\mathrm{NH}^{+}-\mathrm{WW}$

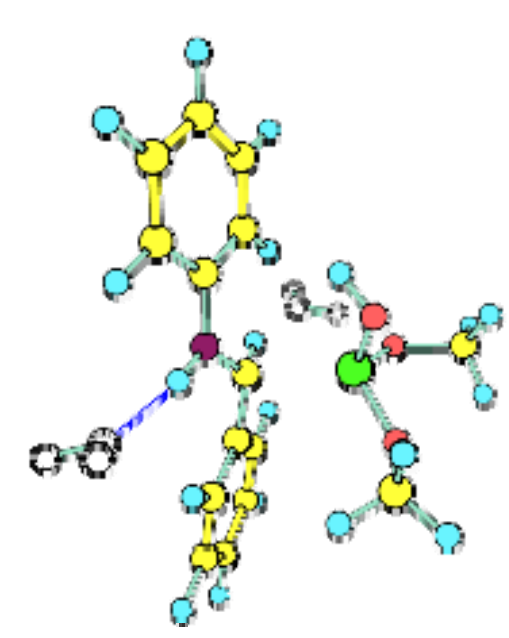

TS(P-C)-WW

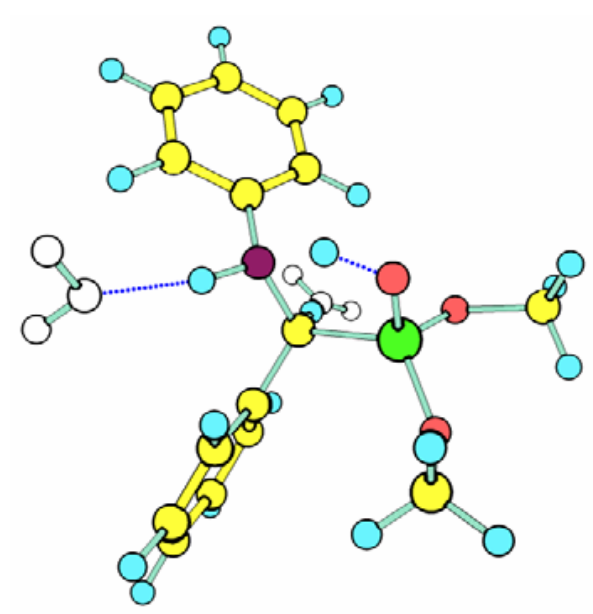

$\mathrm{TS}\left(\mathrm{NH}^{+} \mathrm{O}\right)-\mathrm{WW}$

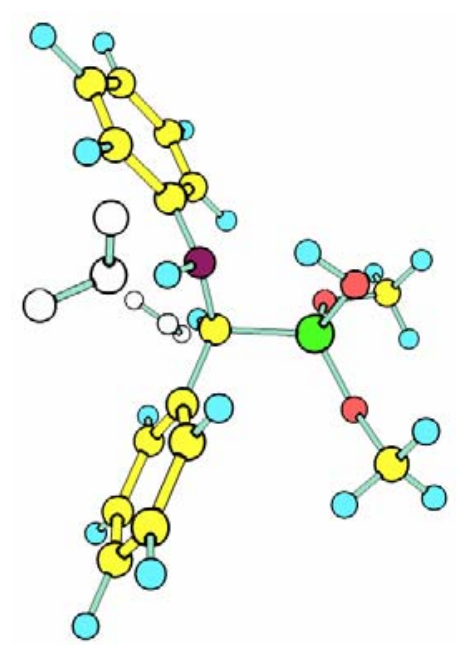

$\mathrm{OH}^{+}-\mathrm{WW}$

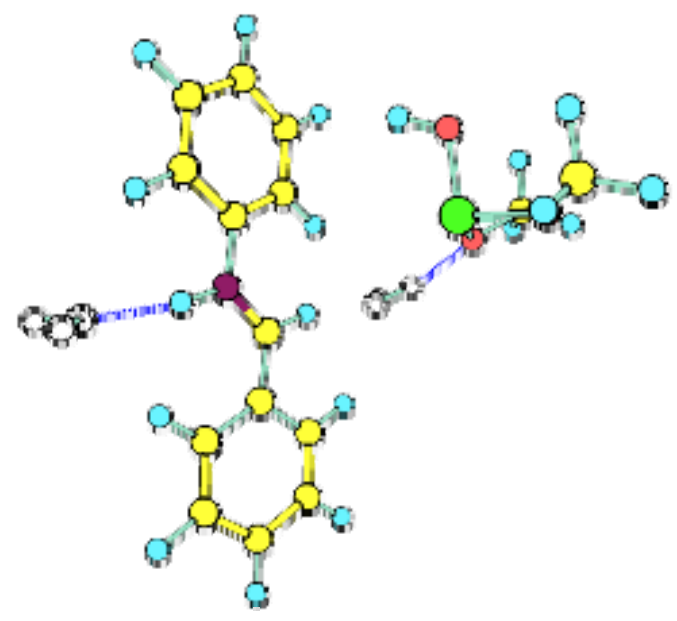

Product-WW

Fig. 7s. The structures including two water molecules in the "explicit" modeling of the reaction pathway representing the first mechanism 